\title{
Effect of Notch signal pathway on H9c2 cardiomyocytes apoptosis induced by hypoxia/ reoxygenation via ROCK2
}

\author{
Yang Shen', Yun Guo Zhou', Xiao Gang Peng ${ }^{2}$, Qing Cao², Kui Hong ${ }^{1 *}$ \\ From 2012 Sino-American Symposium on Clinical and Translational Medicine (SAS-CTM) \\ Shanghai, China. 27-29 June 2012
}

\section{Background}

It is very important to explore the new strategies of prevention and treatment of Ischemic heart disease (IHD) in molecular level. Notch signaling pathways are very expedient in terms of the protection and recovery of myocardial when the heart muscle is impaired. It is also known that ROCKs are closely related to the apoptosis of cardiomyocytes. We infer that there are interactions between Notch signaling pathways and ROCKs on cell apoptosis in H9c2 cardiomyocytes model of $\mathrm{H} / \mathrm{R}$.

\section{Objective}

1. To investigate the effects of Notch signaling pathway on hypoxia/ reoxygenation $(H / R)$ induced apoptosis of H9c2 cardiomyocytes in rat. 2. To explore the interaction between ROCK 2 and NICD on H/R and then to reveal the mechanisms of Notch signaling pathway involved in the modulation of apoptosis and recovery of $\mathrm{H} 9 \mathrm{c} 2$ cardiomyocytes model of $H / R$.

\section{Methods}

1. The total length of cDNA fragment encoded with NICD was obtained from $\mathrm{H} 9 \mathrm{c} 2$ cardiomyocytes from rat by reversing transcription polymerase chain reaction (RT$\mathrm{PCR}$ ), then the cDNA fragment was inserted into pCMVTag2B vector. The recombinant plasmid was confirmed by restriction endonuclease (EcoRI and SalI) digestion and DNA sequencing. H9c2 cardiomyocytes were transfected by pCMV-Tag2B-NICD and the expression of NICD was detected by Western blot. 2. The cultured H9c2 cardiomyocytes were randomly divided into six groups: Control

\footnotetext{
*Correspondence: hongkui88@163.com

'Cardiovascular section, the second affiliated of hospital to Nanchang

University, Nanchang, 330006, China

Full list of author information is available at the end of the article
}

group; H/R group; NICD group; NICD+H/R group; DAPT group; DAPT $+\mathrm{H} / \mathrm{R}$ group. Apoptosis of each group was analyzed by flow cytometry (FCM), and Western blot was applied to assess the expression of ROCK2 and NICD proteins.

\section{Results}

1. The recombinant plasmid pCMV-Tag2B-NICD was successfully constructed. After transfection into H9c2 cardiomyocytes, Western blot analysis showed that NICD was highly expressed in $\mathrm{H} 9 \mathrm{c} 2$ cardiomyocytes. 2 . The overexpression of NICD results in a rise of protein expression of NICD, and reduces the protein expression of ROCK2 and apoptosis of H9c2 cardiomyocytes; on the contrary, the supression of NICD leads to a reduction of protein expression of NICD, and increases the protein expression of ROCK2 and apoptosis of H9c2 cardiomyocytes.

\section{Conclusion}

1. The recombinant plasmid pCMV-Tag2B-NICD was successfully constructed. 2 . After hypoxia/reoxygenation, the protein expression of NICD was significantly increased, and the protein expression of ROCK2 was decreased, compared to control group. 3. Notch signaling pathway reduced the H/R-induced apoptosis of rat H9c2 cardiomyocytes via supression of ROCK2 from the rat.

\section{Author details}

${ }^{1}$ Cardiovascular section, the second affiliated of hospital to Nanchang University, Nanchang, 330006, China. ${ }^{2}$ The Key Laboratory of Molecular Medicine, The Second Affiliated Hospital of Nanchang University, Nanchang, 330006, China.

Published: 17 October 2012 
doi:10.1186/1479-5876-10-S2-A62

Cite this article as: Shen et al: Effect of Notch signal pathway on H9c2

cardiomyocytes apoptosis induced by hypoxia/reoxygenation via

ROCK2. Journal of Translational Medicine 2012 10(Suppl 2):A62.

Submit your next manuscript to BioMed Central and take full advantage of:

- Convenient online submission

- Thorough peer review

- No space constraints or color figure charges

- Immediate publication on acceptance

- Inclusion in PubMed, CAS, Scopus and Google Scholar

- Research which is freely available for redistribution

Submit your manuscript at 